\title{
Unraveling Contradictions: Which Glosses Facilitate Reading Comprehension Among ELLs, and Why?
}

\author{
Andrea Lofgren \\ Georgia State University, Atlanta, GA, United States
}

\begin{abstract}
This critical literature review provides study details for 36 studies examining the effect of glossing for language acquisition among English language learners (ELLs). Useful tables include specificity of participants, gloss types, target vocabulary items and text information about all studies. An analysis of these studies reveals that glossing is an effective means to enhance reading comprehension among ELLs. However, gloss language - whether L1 or English, may depend on learner factors. Other findings include the importance of proximity of gloss to text and the need for glosses that do not require readers to leave the text to access meaning. Considerations such as text genre, text length, targeted items for glossing, number of items to gloss, and gloss presentation are also examined and discussed, including which gloss types may result in trade-offs when glossing is used as a means to promote incidental vocabulary acquisition through independent reading. Several recommendations for further research are offered.
\end{abstract}

Index Terms - glossing, gloss types, gloss presentation, gloss language, glossing literature review

\section{INTRODUCTION}

The word gloss has its origins in Greek as "language" but was adopted into Latin as "a difficult word to be explained" (Blom, 2017, p. 10). Its origin has given rise to multiple English definitions in use today when applied to language and literacy studies, with paratext - textual or visual extras that are not inherently part of the text itself (Genette \& Maclean, 1991) - being the common component. Glosses may appear as marginal annotations or may provide definitions for readers (Stewart \& Cross, 1991). They are an essential aspect of ancient text analysis and are nearly universal among written languages (Blom, 2017). In English texts, the earliest glosses often provide English translations to Latin words. Thus, although English glossing is sometimes perceived to be a type of conversation between readers and texts that transpires in the margins of a text, its history is replete with examples of its use in providing ease for readers in the form of simplifying difficult words or phrases, especially through translation. Language researchers (e.g., Farvardan \& Biria, 2011; Juliana, 2018; Schmitt, 2010; Vela, 2015) have proposed that the glossing of texts assists readers in avoiding incorrect inferencing, thereby leading to greater comprehension. Gardner (2007) demonstrated that adapted definitions better assist reading comprehension than context clues, which are particularly ineffective for second language learners (Kaivanpanah \& Alavi, 2008).

The intentional glossing of texts for language teaching is wrought with decisions such as where to place the gloss, whether to include images, which language to use, and how many words to gloss. Other considerations include the impact of electronic glosses and the role of learner proficiency level in making such decisions. To find answers, an EBSCO abstract search using the terms "gloss" and "reading" was conducted. After removing duplicates, 714 peerreviewed articles, books, and book chapters remained. Articles referencing alternative definitions of gloss (e.g., "gloss over"), book reviews, articles describing marginalia of ancient manuscripts, and articles describing studies in nonEnglish learning contexts were then removed, leaving 387 peer reviewed articles, books, and book chapters from which 127 empirical studies, reviews, and meta-analyses examining reading behavior and glosses were gleaned. The review of literature revealed that glossing is indeed a popular topic for English language research.

\section{LITERATURE REVIEW INCLUSION CRITERIA}

The inclusion criteria for the empirical studies chosen from the original 127 were that the study was peer-reviewed and that it examined glossing for the purpose of English learners' reading comprehension. After removing studies defining glossing as text annotation by students (See Davaribina et al., 2016; Gunobgunob-Mirasol, 2014; Juliana, 2018; Kazandijian, 2017; Minaabad, 2016; Sarabi, 2012), a study in which only the reading of single glossed items while listening was involved (Çakmak \& Erçetin, 2018), a study comparing glosses to learning activities without the use of a control group (e.g., Dehdari \& Sadeghoghlo, 2018), four studies describing learner behavior in gloss context (Jung \& Révész, 2018; Kang et al., 2020; O’Donnell, 2012), a study taking part in a native English language context (Magreehan, 2016), and 78 studies examining glossing solely for vocabulary acquisition-a second popular area of glossing research-36 studies remained. Studies comparing glossing conditions for the sake of vocabulary acquisition alone 
often encourage the interruption of text for deeper processing of words encountered. Consequently, the same mechanism that may lead to gains in degrees of vocabulary knowledge of targeted terms may also hinder comprehension of texts, a notion borne out in several studies finding gains in vocabulary acquisition alongside relatively lower comprehension scores or vice versa (e.g., Akbulut, 2007; Çakmak \& Erçetin, 2018; Cha, 2007; Cheng \& Good, 2009; Dilenschneider, 2017; Hamdi, 2015; Zarei \& Mahmoodzadeh, 2014; Yanguas, 2009; Zolfagharijjooya, 2013). For this reason, studies of vocabulary acquisition alone were omitted to focus solely on how glosses impact reading comprehension. However, studies examining the impact of glossing on both vocabulary and reading comprehension have been included. For these studies, only reading comprehension findings are reported.

Six meta-analyses and three extant literature reviews were located. Unfortunately, several are dated (e.g., Abraham, 2008; Davis, 1989; Taylor, 2002; Taylor 2006), and several are confined to only one aspect of glossing research. For instance, Kim et al.'s (2020) review only includes studies of reading comprehension when vocabulary learning is included, whereas Taylor (2020), Taylor (2014), and Wang (2020) examine literature with a focus only on glosses incorporating technology. The findings in these analyses are certainly useful. However, being narrow in scope, they cannot generalize beyond their scope about how gloss locations, gloss languages, and gloss types may interact to affect reading comprehension. Moreover, extant reviews often lack criticality and are far from comprehensive, whereas my critical review examines 36 studies.

These empirical studies are arranged by foci: those reporting on the general efficacy of glosses, gloss location comparison studies, studies comparing the language of gloss-whether L1 or English — and glosses comparing gloss types. Table 1 relays information about study foci.

TABLE 1

STUDY FOCI

\begin{tabular}{|c|c|}
\hline Study & Focus \\
\hline AbuSeileek (2008) & Gloss Location Comparison \\
\hline Akbulut (2007) & Gloss Type Comparison \\
\hline Al Ghafli (2011) & Gloss Type Comparison \\
\hline Alharbi (2018) & Gloss Language Comparison \\
\hline Arpaci (2016) & Gloss Language Comparison \\
\hline Azari et al. (2012) & Gloss Language Comparison \\
\hline Babaie Shalmani \& Razmjopo (2015) & Gloss Type Comparison \\
\hline Babaie Shalmani \& Sabet (2010) & Gloss Type Comparison \\
\hline Cha (2007) & General Gloss Efficacy \\
\hline Chen \& Yen (2013) & Gloss Location Comparison \\
\hline Cheng \& Good (2009) & Gloss Location and Language Comparison \\
\hline Dilenschneider (2017) & Gloss Type Comparison \\
\hline Elekaei et al. (2015) & Gloss Location Comparison \\
\hline Fahimipour \& Hashemian (2013) & Gloss Language Comparison \\
\hline Farvardin \& Biria (2011) & Gloss Language and Type Comparison \\
\hline Hamdi (2015) & Gloss Type Comparison \\
\hline Hashemian \& Fadaei (2013) & Gloss Language Comparison \\
\hline Jenpattarakul (2012) & General Gloss Efficacy \\
\hline Karbalaei \& Zare (2019) & Gloss Type Comparison \\
\hline Karimvand (2019) & Gloss Type Comparison \\
\hline Karimvand (2020) & Gloss Type Comparison \\
\hline Кo (2005) & Gloss Language Comparison \\
\hline Kongtawee \& Sappapan (2018) & Gloss Language Comparison \\
\hline Lee et al. 2016 & Gloss Type Comparison \\
\hline Levine et al. (2004) & Gloss Type Comparison \\
\hline Majuddin (2014) & Gloss Density \\
\hline Marefat et al. (2016) & Gloss Location Comparison \\
\hline Marzban (2011) & Gloss Type Comparison \\
\hline Melhi, 2014 & General gloss efficacy \\
\hline Sadeghi \& Ahmadi (2012) & Gloss Type Comparison \\
\hline Sadeghi et al. (2017) & Gloss Type Comparison \\
\hline Salimi \& Elham Sadat (2019) & Gloss Language Comparison \\
\hline Türk \& Erçetin (2014) & Gloss Type Comparison \\
\hline Wang \& Lee (2021) & Gloss Type Comparison \\
\hline Zarei \& Mahmoodzadeh (2014) & Gloss Type Comparison \\
\hline Zolfagharijjooya (2013) & Effect of Word Class on General Gloss Efficacy \\
\hline
\end{tabular}

\section{STUDIES REVIEWED}

\section{A. Studies of General Glosses Efficacy}

Nearly all studies examined here have found some benefit of glossing to enhance English language learners' reading comprehension. For instance, Türk and Erçetin (2014) and Akbulut (2007) found positive correlations between participants' choice to use available glosses and reading comprehension scores. With few exceptions, gloss studies that include a no-gloss control group (e.g., AbuSeileek, 2008; Alharbi, 2018; Apraci, 2016; Azari, 2013; Azari et al., 2012; Babaei Shalmani \& Razmjopo, 2015; Çakmak \& Erçetin, 2018; Cha, 2007; Chen \& Yen, 2013; Dilenschneider, 2017; 
Karbalaei \& Zare, 2019; Karimvand, 2019; Karimvand, 2020; Ko, 2005; Lee et al. 2015, Majuddin, 2014; Melhi, 2014; Sadeghi \& Ahmadi, 2012; Sadeghi et al., 2017; Salimi \& Elham Sadat, 2019; Varol \& Erçetin, 2016; Yanguas, 2009; Zarei \& Mahmoodzadeh, 2014) find statistically significant gains for at least one experimental glossing group over a control group without glosses. Studies sometimes report on general gloss efficacy through research designs that compare a single group to multiple reading conditions, include reading without glosses (e.g., Hamdi, 2015; Jenpattarakul, 2012; Marzban, 2011; Wang \& Lee, 2021). Table 2 outlines the findings of these 26 studies.

TABLE 2

GENERAL FINDINGS OF STUDIES WITH CONTROL GROUPS

\begin{tabular}{|c|c|}
\hline Study & Finding \\
\hline AbuSeileek (2008) & Gloss advantage \\
\hline Alharbi (2018) & Gloss advantage \\
\hline Apraci (2016) & Gloss advantage \\
\hline Azari et al. (2012) & Gloss advantage \\
\hline Azari (2013) & Gloss advantage \\
\hline Babaei Shalmani \& Razmjopo (2015) & Gloss advantage \\
\hline Çakmak \& Erçetin (2018) & No advantage \\
\hline Cha (2007) & Gloss advantage \\
\hline Chen \& Yen (2013) & Gloss advantage \\
\hline Dilenschneider (2017) & No advantage \\
\hline Hamdi (2015) & No advantage \\
\hline Jenpattarakul (2012) & Gloss advantage \\
\hline Karbalaei \& Zare (2019) & Gloss advantage \\
\hline Karimvand (2019) & Gloss advantage \\
\hline Karimvand (2020) & Gloss advantage \\
\hline Ko (2005) & Gloss advantage \\
\hline Lee et al. (2015) & Gloss advantage \\
\hline Levine et al. (2004) & Gloss advantage \\
\hline Majuddin (2014) & Gloss advantage \\
\hline Marzban (2011) & Gloss advantage \\
\hline Melhi (2014) & Gloss advantage \\
\hline Sadeghi \& Ahmadi (2012) & Gloss advantage \\
\hline Sadeghi et al. (2017) & Gloss advantage \\
\hline Varol \& Erçetin (2016) & No advantage \\
\hline Wang \& Lee (2021) & Gloss advantage \\
\hline Zarei \& Mahmoodzadeh (2014) & No advantage \\
\hline
\end{tabular}

Of 26, only four find no advantage of glosses to aid in reading comprehension. Nevertheless, in three such studies (i.e., Dilenschneider, 2017; Hamdi, 2015; Zarei \& Mahmoodzadeh, 2014), experimental conditions required participants to leave the field of text to access word meaning, and one additional study, Cha (2007), does not describe the procedures their participants took to access meaning for glosses, despite the importance of gloss location in identifying advantages for the glossing of texts - when individuals are removed from reading for a long period of time for the sake of accessing word meaning, text comprehension may be jeopardized. These studies are described in more depth within their respective areas of foci.

Two studies, Melhi (2014) and Cha (2007) examined the general efficacy of glossing for reading comprehension by simply comparing one group using glosses to a group without glosses. Over a 16-week period, Melhi's (2014) participants took part in one of two reading conditions: one group reading electronic texts with glossing available and another in a traditional classroom, where participants were pre-taught unfamiliar vocabulary before reading. Melhi compared reading comprehension scores between pre- and posttests and conducted a stepwise multiple regression analysis, finding that $41.8 \%$ of variance in improvement was attributed to e-glosses. On the other hand, Cha (2007) found no advantage for a group using glosses to comprehend expository texts. However, Cha proposes that participant's knowledge of the terms chosen for glossing may not have been needed for text comprehension; the glossed words were chosen based on participants' earlier identification of unknown words in the texts, not on the semantic significance of glossed words to text comprehension. Unfortunately, neither Cha nor Melhi (2014) describe the location of glosses, nor do they note whether the gloss language was the learners' first language (L1) or English.

\section{B. Studies of Gloss Location}

Six studies having investigated the effect of gloss location on reading comprehension were located. AbuSeileek (2008) measured the effect of gloss placement as marginal, post-text, at the bottom of the screen, or as a pop-up window when clicked, finding the greatest comprehension for the group with glossing appearing in the margin. Comparing interlinear glosses and marginal glosses in electronic format, Marefat et al.'s (2016) Persian-speaking ELLs had greater comprehension when glosses were interlinear, with a large effect size. Elekaei et al.'s (2015) four-group study compared the efficacy of glosses as footnotes, glosses in margins, glossaries, and interlinear glosses among English learners to find that interlinear glossing led to higher rates of reading comprehension than did all other gloss locations. These results, like AbuSeileek (2008) and Marefat et al. (2016), seem to suggest that when it comes to gloss location, proximity may play a role in glossing efficacy. The mean values for reading comprehension results in Elekaei et al.'s (2015) study were, in descending order: interlinear, margins, footnotes, and a separate glossary. 
One study challenges research finding proximity related to gloss efficacy. Cheng and Good's (2009) study compared a control group to gloss locations in three experimental conditions - in-text, marginal (described as appearing below the text) and as a glossary appearing on a separate page. Although all groups outperformed the control group, with the interlinear gloss group having the largest differential, no statistical significance was found among gloss type $(p=.082)$. However, despite having four measured proficiency levels, most of Cheng and Good's participants read the same text. Furthermore, the researchers propose that the number of words glossed "may have been too many" (p. 126) for the text length, which may have diverted attention to word meaning at the expense of comprehension. They also explain that a reading comprehension test with only five questions might have been too few to "discriminate effectively" among their participants (p. 126).

\section{Studies of Gloss Language}

Several studies have examined the effect of gloss language to compare the efficacy of using translations into the participants' L1 as glosses with using English glosses, often finding an advantage for L1 glosses in both tertiary (e.g., Alharbi, 2018; Arpaci, 2016; Fahimipour \& Hashemian, 2013; Hashemian \& Fadei, 2013; Karimvand, 2020; Salimi \& Elham Sadat, 2019) and secondary (Kongtawee \& Sappanpan, 2018) contexts. Finding struggling students largely absent from extant studies, Kongtawee and Sappapan's (2018) study of Thai students found L1 glosses more effective among 199 struggling secondary English learners. During Salimi and Elham Sadat's (2019) semi-structured interviews, learners stated that $\mathrm{L} 1$ glosses afforded them advantages in that it saved time and reduced anxiety.

On the other hand, Ko's (2005) study of 94 Korean students reading a nonfiction narrative found English glosses superior to L1 glosses, although Ko believes that proficiency level may have played a role. Like Cheng and Good (2009), Ko also expressed concerns about the terms chosen for glossing, stating, "solely determining the target words by the frequency of marks of unknown words is not enough because it may not always represent the most important words in a given context" (p. 133). Ko's study therefore highlights context as an important consideration when choosing which words to gloss. Azari et al. (2012) found no statistical difference between L1 and English gloss use.

As part of a gloss type study, Farvardin and Biria (2011) incorporated L1 (Persian) and English glosses to measure the effect of text genre on gloss efficacy to find the optimal language of the gloss dependent on genre. When reading narratives, L1 glosses led to greater comprehension, yet for expository texts, English glosses led to greater comprehension. In a follow-up questionnaire, participants expressed a slight preference for English glosses over L1 glosses. Farvardin and Biria's (2011) findings call needed attention to the potential interaction effects that may occur between text genre and gloss language.

\section{Studies of Gloss Type Comparison}

Dual coding theory (Paivio, 1991) holds that mental representations of concepts may be held in the mind both visually and verbally, as two types of information processed differently, and neuroscience has since provided substantial support of this theory (e.g., Crosson et al., 2010). Dual coding theory's relevance for reading comprehension lies in its implication that a learner may better comprehend and recall information when presented through multimedia. Numerous studies have tested dual coding theory in glossing context through comparisons of glosses as different multimedia types. For instance, Babaie Shalmani and Razmjopo (2015), Babaie Shalmani and Sabet (2010), Karimvand (2019), and Zarei and Mahmoodzadeh (2014) compared the textual glosses to pictures or a combination group incorporating both, with all but one finding the combination of text and pictures superior to either presentation alone. Zarei and Mahmoodzadeh's (2014) comparison of in-tact classes of lower intermediate Persian high school students found that although glossing groups performed better than the control group, there was no statistical significance found among groups for reading comprehension. However, participants were provided with definitions taken from the Oxford Elementary Learner's Dictionary rather than synonyms or L1 translations. Babaie Shalmani and Razmjopo (2015) argue that providing glosses reduces the reader's cognitive load, allowing for "a greater portion of the working memory capacity ... allocated to processing higher-order comprehension skills" (p. 23). On the other hand, when learners' reading is interrupted long enough to read a multiword definition, returning to the text may tax a learner's fluency in comprehension. Furthermore, research has demonstrated that dictionary definitions may often be more difficult to learners than the word being defined (Kelley et al., 2010; Restrepo Ramos, 2015).

Thus, it may be of little surprise that the findings of studies incorporating animation and video to the mix have found them less reliable for reading comprehension than simple text or pictures (e.g., Abdulut, 2007; Al Ghafli, 2011; Sakar \& Erçetin, 2005; Sato, 2016; Wang \& Lee, 2021), even when leading to greater vocabulary acquisition. It is worth noting that $74 \%$ of Abdulut's (2007) Turkish participants "indicated that they would not have understood either some of the material or most of the material if the material had not been supported with annotations" (p. 513). Although Marzban's (2011) incorporation of video as multimedia found a benefit, the comparison group used paper-based dictionaries, which also require learners to leave the text to access meaning. A similar explanation may be offered for the results of Dilenschneider's (2017) comparison of gloss types, which required all learners, regardless of experimental group, to take steps that temporarily removed them from the reading through hypertexts - one to access dictionary definitions, the other to type the word into a box to access meaning - with no difference found. Dilenschneider's participants also read different texts, depending on the group. Perhaps a better approach would have been using different participants reading 
the same passage. This would have lessened the risk of some target words being easier than others or more important to comprehending the reading than others.

Four studies compared the impact of audio to other gloss presentations. Karbalaei and Zare (2019) found that audio outperformed pictures; Sadeghi et al. (2012) found that learners presented with both pictures and audio outperformed either alone. Sadeghi and Ahmadi (2012) found an advantage when learners had access to extended audio. On the other hand, in a study comparing English definitions to English definitions accompanying audio, accompanying video, or accompanying pictures, Wang and Lee (2021) found that the video group showed a small advantage, although not statistically significant. When participants were asked on a Likert scale to rate the helpfulness of glosses, most reported that they found glosses helpful or extremely helpful, with little variation among gloss type groups.

Zolfagharijooya et al. (2013) measured the effect of word class on glossing efficacy in a seven-week study comparing four groups, with each group exposed to 10 glossed words having a different part of speech-nouns, verbs, adjectives, and adverbs. Zolfagharijooya et al. did not include a control group, as the focus of their study lay only in comparing word class. The researchers found only minor statistical difference among groups when reading comprehension was measured $(p=.402)$ with a small effect size for the noun group.

\section{Discussion}

The glossing of texts as language instruction preparation is time-consuming, leading some language researchers to wonder if the payoff is worth the effort involved (e.g., Bowles, 2004; Lenders, 2008). Babaie Shalmani and Razmjopo (2015) argue that glossing reduces the cognitive load for readers, and the general findings of glossing studies supports this proposition. Glancing at an interlinear gloss or clicking on a word for a concise pop-up reduces the need for extended periods of interruption and for haphazard contextual guessing. On the other hand, because certain glossing requires brief interruptions of reading, glossing may potentially hamper comprehension in some contexts. Foroughi et al. (2015) demonstrated that when reading comprehension is defined as the synthesis of information in long passages, any interruption of reading will disrupt the reader's working memory, thereby leading to poorer comprehension. The literature reviewed seems to support Foroughi et al. (2015) when glosses require readers to move away from the text, whether through hyperlinks to other pages or to a paper dictionary or glossary outside of the text page. When glosses are placed non-interlinearly, readers spend more time away from texts. Consequently, text comprehension may at the very least require a reader to return to previous passages for re-reading. The finding of Farvardin and Biria (2011) that multiple-choice glosses are less effective than other types provides further evidence of this phenomenon. Considering re-reading has itself been proposed as a language learning strategy (Cheng \& Good, 2009), returning to a text for rereading is not necessarily detrimental to language learning in general. However, if the purpose of exposure through reading is for the sake of increasing fluency through independent reading for incidental language learning, gloss placement may be an important consideration. Glosses most effective are simple and with close proximity to the reader's text.

Several studies cited within this review tested reading comprehension by asking participants to recall the text. However, this method has been challenged as disadvantageous for some student groups (e.g., Carlisle, 1999). Furthermore, Chang (2006) demonstrated that translation tasks are a better predictor of reading comprehension among L2 language learners than text recall. Perhaps text recall in addition to a secondary reading comprehension evaluation may offer a more well-rounded understanding of how well a learner has comprehended a given text, a recommendation echoed by Cheng and Good (2009). Indeed, Chen (2016) compared the effect of gloss location on the reading comprehension of 95 participants using both summary writing and multiple choice, finding results dependent upon the method of assessment: in-text glosses outperformed marginal glosses when summary writing was assessed, yet marginal glosses outperformed in-text glosses when participants were assessed using multiple choice testing.

Despite the ever-increasing number of gloss studies being published, several questions still remain, in part because of the absence in reporting study details. First, as can be seen in Table 3, glossing studies often fail to report the length of the text used for the study, making it difficult for readers to critically consider whether the number of glossed words for the text may have created a burden on the reader. Arguably, at a certain point, the interruption of reading that checking numerous glosses requires may be cognitively taxing to readers. Table 3 also reveals an absence in reporting text readability coupled with participant proficiency levels. 
TABLE 3

TEXT INFORMATION

\section{Study}

Akbulut (2007)

Al Ghafli (2011)

Alharbi (2018)

Arpaci (2016)

Azari et al. (2012)

Babaie Shalmani \& Razmjopo (2015)

Babaie Shalmani \&

Sabet (2010)

Cha (2007)

Chen \& Yen (2013)

Cheng \& Good (2009)

Dilenschneider (2017)

Elekaei et al. (2015)

Fahimipour \& Hashemian (2013)

Farvardin \& Biria (2011)

Hamdi (2015)

Hashemian \& Fadaei (2013)

Jenpattarakul (2012)

Karbalaei \& Zare (2019)

Karimvand (2019)

Karimvand (2020)

Ko (2005)

Kongtawee \&

Sappapan (2018)

Lee et al. 2016

Levine et al. (2004)

Majuddin (2014)

Marefat et al. (2016)

Marzban (2011)

Melhi (2014)

Sadeghi \& Ahmadi (2012)

Sadeghi et al. (2017)

Salimi \&

Elham Sadat (2019)

Türk \& Erçetin (2014)

Wang \& Lee (2021)

Zarei \&

Mahmoodzadeh (2014)

Zolfagharijjooya (2013)

\section{Text Genre}

Canonical Literature

Academic/Expository

Academic/Expository

Academic/Expository

N/R

Academic/Expository

Academic/Expository

Academic/Expository

Academic/Expository

N/R

Academic/Expository

Academic/Expository

N/R

N/R

Narrative; Expository

N/R

N/R

N/R

Academic/Expository

N/R

N/R

Nonfiction Narrative

Academic/Expository

Academic/Expository

Academic/Expository

Academic/Expository

Academic/Expository

Academic/Expository

N/R

Academic/Expository

Academic/Expository

N/R

Academic/Expository

N/A

N/R

Academic/Expository
Average

Readability

Intermediate

Grade 3-4

N/R

Advanced

Grade 7.2

Grade 14.9

N/R

N/R

N/R

Intermediate

Grade 7

Grade 8

Intermediate

TOEFL

Grade 11

N/R

TOEFL

N/R

Intermediate

N/R

Grade 10.5

Grade 10.4

Grade 6.5

Advanced

Advanced

N/R

Pre-Intermed

Grade 8.8

N/R

N/R

Upper-Inter

Grade 7.8

N/R

Advanced

Elementary

Grade 9.2
Readability Measure

ESL Text

Flesch-Kincaid

N/R

Other

Flesch-Kincaid

Flesch-Kincaid

N/R

N/R

N/R

ESL Text

Fry-Graph

Flesch-Kincaid

ESL Text

TOEFL

Flesch-Kincaid

N/R

TOEFL

N/R

Other

ESL Text

Flesch-Kincaid

Flesch-Kincaid

Flesch-Kincaid

ESL Text

N/R

ESL Text

ESL Text

SMOG

N/R

Other

Flesch-Kincaid

Flesch-Kincaid

Other

CET-4

ESL Text

Note: N/R means information not reported; "Other" means that the researcher(s) described a method of ensuring that text readability matched the participant level although no readability was measured; "ESL Test" means that the readability level was determined by the publisher of the text; CET4 refers to the national test of English required for English-instruction university students in China (Zheng \& Cheng, 2008).

As recommended by Taylor (2010), matching readability level with participant level is critical for learner comprehension. As noted in Table 4, glossing studies surprisingly often fail to report the language of the glosses being examined; the addition of this information may help answer the question of which contexts favor L1 glosses and for which contexts English glosses are more advantageous. 


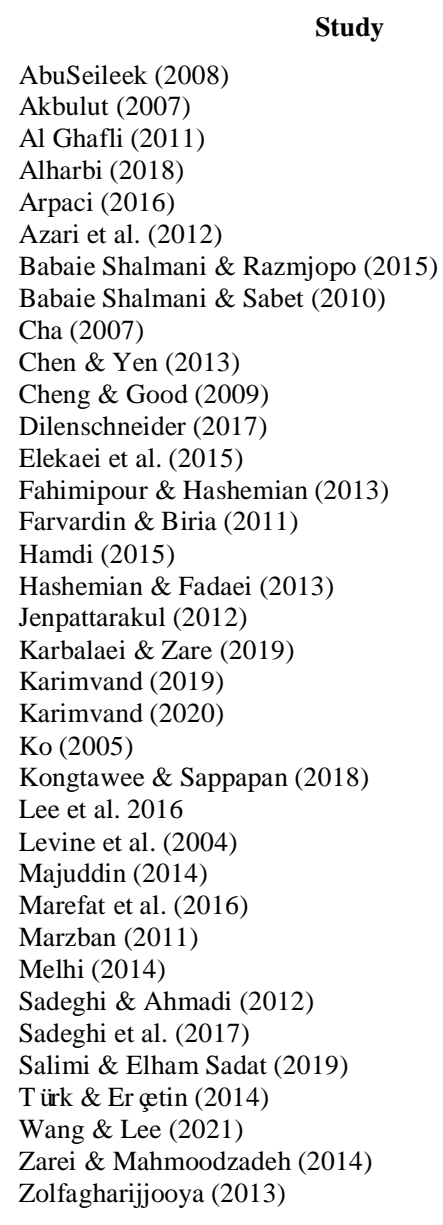

\begin{tabular}{|c|c|c|}
\hline \multicolumn{3}{|c|}{$\begin{array}{c}\text { TABLE } 4 \\
\text { GLOSSING INFORMATION }\end{array}$} \\
\hline $\begin{array}{c}\text { \# of Items } \\
\text { Glossed }\end{array}$ & Gloss Lan & Gloss Location \\
\hline 270 & English & IV \\
\hline 42 & English & Interlinear Pop-up \\
\hline 59 & Arabic; English & Interlinear Pop-up \\
\hline 18 & IV & $N / R$ \\
\hline 16 & IV & $N / R$ \\
\hline 30 & $N / R$ & $N / R$ \\
\hline 153 & $N / R$ & Interlinear Pop-up \\
\hline$N / R$ & $N / R$ & $N / R$ \\
\hline 14 & English & Page Bottom \\
\hline 128 & English & IV \\
\hline 16 & IV & IV \\
\hline 24 & English & Hyperlink \\
\hline 28 & $N / R$ & IV \\
\hline$N / R$ & English; Persian & $N / R$ \\
\hline 60 & IV & $N / R$ \\
\hline$N / R$ & $N / R$ & IV \\
\hline$N / R$ & $\mathrm{~N} / \mathrm{R}$ & $N / R$ \\
\hline$N / R$ & English & $N / R$ \\
\hline 20 & $N / R$ & Margin \\
\hline 21 & Persian & $\mathrm{N} / \mathrm{R}$ \\
\hline 56 & IV & Margin \\
\hline 22 & IV & $N / R$ \\
\hline 40 & IV & Hyperlink \\
\hline 30 & English & Interlinear Pop-up \\
\hline 30 & English & Hyperlink \\
\hline 12 & English & Page Bottom \\
\hline 14 & Persian & IV \\
\hline$N / R$ & $\mathrm{~N} / \mathrm{R}$ & Hyperlink \\
\hline$N / R$ & $N / R$ & Hyperlink \\
\hline 14 & $N / R$ & $\mathrm{~N} / \mathrm{R}$ \\
\hline 24 & English & Margin \\
\hline$N / R$ & $N / R$ & $N / R$ \\
\hline & English & Marginal Pop-up \\
\hline 80 & $N / R$ & IV \\
\hline 30 & $N / R$ & $N / R$ \\
\hline 39 & $N / R$ & Margin \\
\hline
\end{tabular}

\section{RECOMMENDATIONS}

More robust studies that simply compare gloss languages to determine differences in efficacy and the role of learner proficiency in this process would be beneficial to English teachers. Rott (2007) found higher comprehension of main ideas when the same target item was glossed multiple times throughout a German text. Perhaps a replication study of English learners could provide insight into the role of gloss and frequency of target items, particularly one that accounts for dispersion, and second language teachers could benefit from a body of research identifying an optimal range of glossed words for a given text length. Furthermore, of all glossing studies located, none examined the glossing of lexical bundles or collocations to aid in reading comprehension ${ }^{1}$. Finally, English teachers may benefit from examinations of the effect of genre on glossing efficacy, particularly in light of findings by Farvardin and Biria (2011) that gloss language and text genre may have interaction effects.

As can be seen in Table 5, the participants of glossing studies are most often tertiary students or adults enrolled in language institutions. This may explain why only $16 \%$ of glossing studies include individuals with proficiencies below the intermediate level. Thus, more glossing studies of beginning learners as well as those in primary and secondary contexts may be useful. One glossing study, Chen and Yen (2013), suggests that proficiency level may play a role in not only in how effective glossing is for reading comprehension but also in determining which gloss type (e.g., pictorial, textual, or both) is most effective for enhancing reading comprehension. Consequently, glossing studies employing analyses that measure the impact of varied proficiency levels may also help untangle the mixed findings of extant research.

\footnotetext{
${ }^{1}$ Glossing studies of lexical bundles have taken place in other L2 learning contexts (See Bell and LeBlanc, 2000)
} 
TABLE 5

STUDY PARTICIPANTS

\begin{tabular}{|c|c|c|c|c|c|}
\hline Study & L1 & \# & Prof Level & Context & $\begin{array}{c}\text { Proficiency } \\
\text { Measurement }\end{array}$ \\
\hline AbuSeileek (2008) & Arabic & 78 & Intermediate & Tertiary & Other \\
\hline Akbulut (2007) & Turkish & 69 & Advanced & Tertiary & IELTS \\
\hline Al Ghafli (2011) & Arabic & 222 & Intermediate & Adults & Other \\
\hline Alharbi (2018) & Arabic & 72 & $\begin{array}{l}\text { Intermediate; } \\
\text { Advanced }\end{array}$ & Tertiary & Other \\
\hline Arpaci (2016) & Turkish & 81 & Beginner & Secondary & CEFR \\
\hline Azari et al. (2012) & Persian & 76 & Beginner & Tertiary & TOEFL \\
\hline Babaie Shalmani \& Razmjopo (2015) & Persian & 187 & Intermediate & Tertiary & IELTS \\
\hline $\begin{array}{l}\text { Babaie Shalmani \& } \\
\text { Sabet (2010) }\end{array}$ & Persian & 120 & Intermediate & Tertiary & IELTS \\
\hline Cha (2007) & Korean & 26 & Homogeneous & Tertiary & Other \\
\hline Chen \& Yen (2013) & Mandarin & 83 & Homogeneous & Tertiary & GEPT \\
\hline Cheng \& Good (2009) & Chinese & 135 & $* \mathrm{IV}$ & Tertiary & MTELP \\
\hline Dilenschneider (2017) & Japanese & 84 & Low-Intermediate & Tertiary & CEFR \\
\hline Elekaei et al. (2015) & Persian & 140 & Intermediate & Adults & MTELP \\
\hline $\begin{array}{l}\text { Fahimipour \& } \\
\text { Hashemian (2013) }\end{array}$ & Persian & 60 & Homogeneous & Adults & TOEFL \\
\hline Farvardin \& Biria (2011) & Persian & 108 & $\mathrm{~N} / \mathrm{R}$ & Adults & N/R \\
\hline Hamdi (2015) & Arabic & 44 & Homogeneous & Tertiary & Other \\
\hline $\begin{array}{l}\text { Hashemian \& } \\
\text { Fadaei (2013) }\end{array}$ & Persian & 60 & Homogeneous & Adults & TOEFL \\
\hline Jenpattarakul (2012) & Thai & 30 & $\mathrm{~N} / \mathrm{R}$ & Tertiary & $\mathrm{N} / \mathrm{R}$ \\
\hline Karbalaei \& Zare (2019) & Persian & 77 & Intermediate & Tertiary & PET \\
\hline Karimvand (2019) & Persian & 80 & Homogeneous & Secondary & $\mathrm{N} / \mathrm{R}$ \\
\hline Karimvand (2020) & $\begin{array}{l}\text { Persian } \\
\text { Turkish }\end{array}$ & 60 & Advanced & Tertiary & OPT \\
\hline Ko (2005) & Korean & 94 & Intermediate & Adults & Other \\
\hline $\begin{array}{l}\text { Kongtawee \& } \\
\text { Sappapan (2018) }\end{array}$ & Thai & 83 & $\begin{array}{l}\text { Intermediate; } \\
\text { Advanced }\end{array}$ & Secondary & Other \\
\hline Lee et al. 2016 & Korean & 80 & Intermediate & Tertiary & TOEIC \\
\hline Levine et al. (2004) & Hebrew & 55 & Advanced & Tertiary & Other \\
\hline Majuddin (2014) & Multiple & 33 & $\mathrm{~N} / \mathrm{R}$ & primary & N/R \\
\hline Marefat et al. (2016) & Persian & 39 & Beginner & Tertiary & $\mathrm{N} / \mathrm{R}$ \\
\hline Marzban (2011) & Persian & 40 & Beginner & Tertiary & OPT \\
\hline Melhi (2014) & Arabic & 38 & Homogeneous & Tertiary & IELTS \\
\hline Sadeghi \& Ahmadi (2012) & Persian & 60 & Upper-Intermediate & Adults & KEY \\
\hline Sadeghi et al. (2017) & Persian & 135 & Upper-Intermediate & Tertiary & $\mathrm{N} / \mathrm{R}$ \\
\hline Salimi \& Elham Sadat (2019) & Persian & 60 & Intermediate & Adults & $\mathrm{N} / \mathrm{R}$ \\
\hline Türk \& Erçetin (2014) & Turkish & 82 & Upper-Intermediate & Secondary & CEFR \\
\hline Wang \& Lee (2021) & Chinese & 160 & Homogeneous & Tertiary & Other \\
\hline $\begin{array}{l}\text { Zarei \& } \\
\text { Mahmoodzadeh (2014) }\end{array}$ & Persian & 65 & Low-Intermediate & Tertiary & KEY \\
\hline Zolfagharijjooya (2013) & Persian & 100 & Homogeneous & Tertiary & OPT \\
\hline
\end{tabular}

*IV = Independent Variable

Note: OPT refers to the Oxford Placement Test; TOEIC refers to the Test of English for International Communication; IELTS refers to the International English Language Testing System; PET refers to the General English Proficiency Test; MTELP refers to the Michigan Test of English Language Proficiency; GEPT refers to the General English Proficiency Test. "Other" includes local proficiency examinations, cases where proficiency were determined by the researcher, or determinations were made through years of English study, level of English study, or course grades. "N/R" means no explanation was provided for how proficiency was determined. For studies with IV proficiency levels, proficiency levels were included as part of the study.

\section{CONCLUSION}

The body of research on the use of English glosses - defined as providing definitions, visual aids, or translations to assist English language readers with text comprehension-offers evidence that preparing texts in this manner is a promising way to facilitate text comprehension for English learners. Indeed, learners themselves often reveal a preference for having glosses available. Research supports offering both L1 and English glosses to readers and placing them near the words being defined. Words chosen for glossing should be semantically important but sparsely located throughout the text. However, the lack of reporting by many studies on details such as the gloss language, the gloss location, and the genre and length of the text used makes some generalizations difficult, as does the absence of robust studies examining the role and interaction effects of these factors as well as participant proficiency levels in glossing efficacy. Because reading is foundational to English learning, glossing seems to provide an efficient way to enhance readability while assisting readers with incidental language learning. Consequently, determining the ranges and conditions within which English glosses may be best used to enhance such learning seems a worthwhile endeavor. 


\section{REFERENCES}

[1] Abraham, L. B. (2008). Computer-mediated glosses in second language reading comprehension and vocabulary learning: A meta-analysis. Computer Assisted Language Learning, 21(3), 199-226. https://doi.org/10.1080/09588220802090246

[2] AbuSeileek, A. (2008). Hypermedia annotation presentation: learners' preferences and effect on EFL reading comprehension and vocabulary acquisition. CALICO Journal, 25(2), 1-15.

[3] Akbulut, Y. (2007). Effects of multimedia annotations on incidental vocabulary learning and reading comprehension of advanced learners of English as a foreign language. Instructional Science, 32, 499-517. https://doi.org/10.1007/s11251-0079016-7

[4] Al Ghafli (2011). The effect of mediated glosses on vocabulary retention and reading comprehension with English language learners in Saudi Arabia (Publication No. 11413) [Doctoral dissertation, University of Kansas]. ProQuest Dissertations \& Theses Global.

[5] Alharbi (2018). The impact of glossed texts on reading comprehension among tertiary Saudi students. English Language Teaching, 11(3), 153-161. http://doi.org/10.5539/elt.v11n3p153

[6] Arpaci (2016). The effects of accessing L1 versus L2 definitional glosses on L2 learners' reading comprehension and vocabulary learning. Eurasian Journal of Applied Linguistics, 2(1), 15-29.

[7] Azari, F. (2013). Effects of textual glosses on text comprehension, vocabulary gain and vocabulary retention among tertiary level Persian-speaking ESL learners. (Publication No. FBMK 2013 22) [Doctoral dissertation, Universiti Putra Malaysia].

[8] Azari, F., Abdullah, F., \& Hoon, T. B. (2012). Effects of textual glosses on reading comprehension of low proficiency EFL postgraduates. The English Teacher, XLI (1), 42-55.

[9] Babaie Shalmani, H., \& Razmjopo, S. A. (2015). Multimedia annotation: Comparability of gloss modalities and their implications for reading comprehension. Journal of English Language Teaching and Learning, 15. Article 15.

[10] Babaie Shalmani, H., \& Sabet, M. K. (2010). Pictorial, textual, and picto-textual glosses in e-reading: A comparative study. English Language Teaching, 3(4), 195-203.

[11] Bell, F., \& LeBlanc, L. B. (2000). The language of glosses in L2 reading on computer: Learners' preferences. Hispania, 83(2) 274-285.

[12] Blom, A. H. (2017). Glossing the Psalms: The emergence of the written vernaculars in Western Europe from the seventh to the twelfth centuries. De Gruyter.

[13] Çakmak, F., \& Erçetin, G. (2018). Effects of gloss type and text recall and incidental vocabulary learning in mobile-assisted L2 listening. ReCALL, 30(1), 24-47.

[14] Cha (2007). Facilitating effect of online dictionary glossing on vocabulary learning and reading comprehension for EFL learners. Multimedia Assisted Language Learning, 10(3), 9-26. https://doi.org/10.15702/MALL.2007.10.3.9

[15] Chang, Y-F. (2006). On the use of the immediate recall task as a measure of second language reading comprehension. Language Testing, 23(4), 520-543. https://doi.org/10.1191/0265532206lt340oa

[16] Chen, I-J., \& Yen, J-C. (2013). Hypertext annotation: Effects of presentation formats and learner proficiency on reading comprehension and vocabulary learning in foreign languages. Computers \& Education, 63, 416-423. https://doi.org/10.1016/j.compedu.2013.01.005

[17] Chen, I-J. (2016). Hypertext glosses for foreign language reading comprehension and vocabulary acquisition: Effects of assessment methods. Computer Assisted Language Learning, 29(2), 413-426. https://doi.org/10.1080/09588221.2014.983935

[18] Cheng, Y-H., \& Good, R. L. (2009). L21 glosses: Effects on EFL learners' reading comprehension and vocabulary retention. Reading in a Foreign Language, 21(2), 119-142.

[19] Crosson, B., Ford, A., McGregor, K. M., Meinzer, M., Cheshkov, S., Li, X., Walker-Batson, D., Briggs, R. W. (2010). Functional imaging and related techniques: An introduction for rehabilitation researchers. The Journal of Rehabilitation Research and Development, 47(2), vii-xxxiv. https://doi.org/doi:10.1682/jrrd.2010.02.001

[20] Davaribina, M., Shabani Minaabad, M., \& Orooji, N. (2016). The effect of graphic organizers and marginal glossing on reading comprehension of texts with sequential structure. Modern Journal of Language Teaching Methods, 6(6), 461-470.

[21] Davis, J. N. (1989). Facilitating effects of marginal glosses on foreign language reading. The Modern Language Journal, 73(1), 41-48.

[22] De Ridder, I. (2002). Visible or invisible links: does the highlighting of hyperlinks affect incidental vocabulary learning, text comprehension, and the reading process? Language Learning \& Technology, 6(1), 123-146.

[23] Dehdari, E., \& Sadeghoghlo, H. (2018). Comparing effect of concept mapping and marginal glossing on EFL learners' reading comprehension and vocabulary retention. Journal of Applied Linguistics and Language Research, 5(1), 328-338.

[24] Dilenschneider, R. F. (2017). Examining the conditions of using an on-line dictionary to learn words and comprehend texts. ReCALL, 30(1), 4-23.

[25] Elekaei, A., Faramarzi, S., \& Koosha, M. (2015). The impact of gloss types on reading comprehension, vocabulary gain and vocabulary retention: A comparative study. International Journal of Applied Linguistics \& English Literature, 4(5), 97-103. https://doi.org/10.7575/aiac.ijalel.v.4n.5p.97

[26] Fahimipour, N., \& Hashemian, M. (2013). The effect of lexical glossing types on reading and listening skills of Iranian EFL learners. Journal of Language Teaching and Research, 4(1), 192-199. https://doi.org/10.4304/j1tr.4.1.192-199

[27] Farvardin, M. T., \& Biria, R. (2011). Textual glosses, text types, and reading comprehension. Theory and Practice in Language Studies, 1(10), 1408-1415. https://doi.org/10.4304/tpls.1.10.1408-1415

[28] Gardner, D. (2007). Children's immediate understanding of vocabulary: Contexts and dictionary definitions. Reading Psychology, 28(4), 331-373. https://doi.org/10.1080/02702710701260508

[29] Genette, G., \& Maclean, M. (1991). Introduction to paratext. New Literary History, 22(2), 261-272. https://doi.org/10.2307/469037

[30] Gunobgunob-Mirasol, R. (2014). The relative effect of glossing instruction on college students' reading comprehension. $3^{\text {rd }}$ International Conference on Linguistics, Literature and Culture (pp. 82-90). Procedia Social and Behavioral Sciences. 
[31] Hamdi, C. (2015). The effects of electronic dictionary use on reading comprehension and vocabulary retention of EFL students. In K. Al-Zubaidi (Ed.), Bejaia University First International Conference Proceedings (pp. 180-191). Arab World English Journal.

[32] Hashemian, M., \& Fadaei, B. (2013). The effect of lexical glossing types on Persian L2 learners' reading and listening. Procedia Social and Behavioral Sciences, 70, 490-500.

[33] Jenpattarakul, W. (2012). Does glossing affect Thai EFL students' reading comprehension and lexis acquisition? Mediterranean Journal of Social Sciences, 3(11), 111-118. https://doi.org/10.5901/mjss.2012.v3n11p111

[34] Juliana. (2018). The comparative impacts of using lexical glossing and inferencing strategies on students' reading comprehension. Advances in Language and Literacy Studies, 9(1), 1-4. https://doi.org/10.7575/aiac.alls.v.9n.1p.1

[35] Jung, J., \& Révész, A. (2018). The effects of reading activity characteristics on L2 reading processes and noticing of glossed construction. The effects of reading activity characteristics on L2 reading processes and noticing of glossed constructions. Studies in Second Language Acquisition, 40(4), 755-780.

[36] Kaivanpanah, S., \& Alavi, M. (2008). Deriving unknown word meaning from context: Is it reliable? RELC Journal, 39(1), 7795.

[37] Kang, H., Kweon, S-O., \& Choi, S. (2020). Using eye-tracking to examine the role of first and second language glosses. Language Teaching Research. https://doi.org/10.1177\%2F1362168820928567

[38] Karbalaei, A., \& Zare, A. (2019). A comparison of the effect of textual, audio, and textual-pictorial and audio-pictorial annotations on enhancing reading comprehension among Iranian EFL learners. Teaching English with Technology, 19(3), 4067.

[39] Karimvand, M. (2019). The effect of gloss on EFL learners' reading comprehension. Specialty Journal of Language Studies and Literature, 3(2), 38-43.

[40] Karimvand, M. (2020). The effect of different types of marginal glossing (first language \& second language) and pictorial glossing on Iranian and Turkish English as a foreign language learners' reading comprehension. PJAEE, 17(9), 9301-9317.

[41] Kazandjian, K. W. (2017). The effect of semantic learners mapping and lexical glossing on reading comprehension of Egyptian EFL. Hermes, 6(1), 43-96. https://doi.org/10.21608/herms.2017.76966

[42] Kelley, J. G., Lesaux, N. K., Kieffer, M. J., \& Faller, S. E. (2010). Effective academic vocabulary instruction in the urban middle school. The Reading Teacher, 64(1), 5-14. https://doi.org/10.1598/RT.64.1.1

[43] Khezrlou, S., Ellis, R., \& Sadeghi, K. (2017). Effects of computer-assisted glosses on EFL learners' vocabulary acquisition and reading comprehension in three learning conditions. System, 65, 104-116. https://doi.org/10.1016/j-system.2017.01.009

[44] Kim, H. S., Lee, J. H., \& Lee, H. (2020). The relative effects of L1 and L2 glosses on L2 learning: A meta-analysis. Language Teaching Research. Advance online publication. https://doi.org/10.1177\%2F1362168820981394

[45] Ko, M. H. (2005). Glosses, comprehension, and strategy use. Reading in a Foreign Language, 17(2), 125-143.

[46] Kongtawee, P., \& Sappapan, P. (2018). The effects of L1 and L2 hypertext glosses on reading comprehension and vocabulary retention among Thai secondary school students. Arab World English Journal, 9(3), 367-380. https://doi.org/10.24093/awej/vol9no3.24

[47] Lee, H., Lee, H., \& Lee, J. H. (2016). Evaluation of electronic and paper textual glosses on second language vocabulary learning and reading comprehension. Asia-Pacific Educational Research, 25(4), 499-507. https://doi.org/10/1007/s40299-0150270-1

[48] Levine, A., Bejarano, Y., Carrell, P., \& Vered, L. (2004). Comparing dictionary definitions and glosses in hypertext foreign language reading: Facilitating foreign language reading comprehension and vocabulary acquisition. CATESOL Journal, 16(1), 59-68.

[49] Lomicka (1998). To gloss or not to gloss: An investigation of reading comprehension online. Language Learning \& Technology, 1(2), 41-50.

[50] Loucky, J. P., \& Tuzi, F. (2010). Comparing foreign language learners' use of online glossing programs. International Journal of Virtual and Personal Learning Environments, 1(4), 31-51. https://doi.org/10.4018/jvple.2010100103

[51] Magreehan, D. A. (2016). Presentation of electronic glosses: Effects on student learning and monitoring from text. (Publication No. 73659) [Doctoral dissertation, Texas Tech University]. ProQuest Dissertations \& Theses Global.

[52] Majuddin, E. (2014). The effects of differing densities of glossing on vocabulary uptake and reading comprehension. Advances in Language and Literacy Studies, 5(6), 132-152. https://doi.org/10.7575/aiac.alls.v.5n.6p.132

[53] Marefat, H., Rezaee, A. A., \& Naserieh, F. (2016). Effect of computerized gloss presentation format on reading comprehension: A cognitive load perspective. Journal of Information Technology Education: Research, 15, 479-501

[54] Marzban, A. (2011). Investigating the role of multimedia annotations in EFL reading comprehension. Procedia - Social and Behavioral Sciences, 28, 72-77. https://doi.org/10.1016/j.sbspro.2011.11.015

[55] Melhi, (2014). Effects on predictability of computer-mediated glosses in reading comprehension of EFL college students. Reading Matrix: An International Online Journal, 14(2), 65-77.

[56] O'Donnell, M. E. (2012). Second language learners' use of marginal glosses. Foreign Language Annals, 45(4), 543-563. https://doi.org/10.1111/j.1944-9720.2013.12004.x

[57] Paivio, A. (1991). Dual coding theory: Retrospect and current status. Canadian Journal of Psychology/Revue Canadienne de psychologie, 45(3), 255-287.

[58] Pathan, H., Khatoon, S., Arslan Raheem, M., Dar, F., \& Mushtaq, F. (2021). Impacts of multimedia gloss on learning reading comprehension in ESL context. Ilkogretim Online - Elementary Education Online. https://doi.org/10.17051/ilkonline.2021.03.22

[59] Restrepo Ramos, F. D. (2015). Incidental vocabulary learning in second language acquisition: A literature review. PROFILE Issues in Teachers' Professional Development, 17(1), 157-166. https://doi.org/10.15446/profile.v17n1.43957

[60] Rott, S. (2007). The effect of frequency of input-enhancements on world learning and text comprehension. Language Learning, 57(2), 165-199. 
[61] Sadeghi, K., \& Ahmadi, N. (2012). The effect of gloss type and mode on Iranian EFL learners' reading comprehension. English Language Teaching, 5(12), 100-110. https://doi.org/10.5539/elt.v5n12p100

[62] Sadeghi, K., Khezrlou, S., \& Modirkhameneh, S. (2017). Calling Iranian learners of L2 Eng. different learning conditions. Journal of Research in Reading, 40(1), 566-586. https://doi.org/10.1111/1467-9817.12088

[63] Sakar, A., \& Erçetin, G. (2005). Effectiveness of hypermedia annotations for foreign language reading. Journal of Computer Assisted Learning, 21(1), 28-38. https://doi.org/10.1111/j.1365-2729.2005.00108.x

[64] Salimi, E. A., \& Elham Sadat, M. (2019). The effect of L1 glosses for abstract words on English reading comprehension. Reading Matrix: An International Online Journal, 19(1), 181-196.

[65] Sarabi, Z. R., \& Beheshti, S. (2012). The effect of graphic organizers and marginal L2 glossing training on the reading comprehension of ESP students. Researcher, 4(4), 16-23.

[66] Schmitt, N. (2010). Researching vocabulary. University of Nottingham.

[67] Stewart, R. A., \& Cross, T. L. (1991). The effect of marginal glosses on reading comprehension and retention. Journal of Reading, 35(1), 4-12.

[68] Taylor, A. M. (2002). A meta-analysis on the effects of L1 glosses on L2 reading comprehension. (Publication No. 3099215) [Doctoral dissertation, Purdue University]. ProQuest Dissertations \& Theses Global.

[69] Taylor, A. (2006). The effects of CALL versus traditional L1 glosses on L2 reading comprehension. CALICO Journal, 23(2), 309-218.

[70] Taylor, A. (2013). CALL versus paper: In which context are L1 glosses more effective? CALICO Journal, 30(1), 63-81. https://doi.org/10.11139/cj.30.1.63-81

[71] Taylor, A. M. (2014). Glossing frequency and L2 reading comprehension: The influence of CALL glossing. CALICO Journal, 31(3), 374-389. https://doi.org/10.11139/cj.31.3.374-389

[72] Taylor, A. M. (2020). Technology and reading: The effects of CALL glossing. Psychological Reports, 124(5), $2092-2118$. https://doi.org/10.1177/0033294120954139

[73] Taylor, A. M. (2010). Glossing is sometimes a distraction: Comments on Cheng and Good (2009). Reading in a Foreign Language, 22(2), 353-354.

[74] Türk, E., \& Erçetin, G. (2014). Effects of interactive versus simultaneous display of multimedia glosses on L2 reading comprehension and incidental vocabulary learning. Computer Assisted Language Learning, 27(1), 1-25. https://doi.org/10.1080/09588221.2012.692384.

[75] Varol, B., \& Erçetin, G. (2016). Effects of working memory and gloss type on L2 text comprehension and incidental vocabulary learning in computer-based reading. Procedia - Social and Behavioral Science, 232, 759-768. https://doi.org/10.1016/j.sbspro.2016.10.103

[76] Vela, V. (2015). Using glosses for incidental vocabulary acquisition. Procedia - Social and Behavioral Sciences, 199, 305-310. https://doi.org/10.1016/j.sbspro.2015.07.551

[77] Wang \& Lee (2021). Multimedia gloss presentation: Learners' preference and the effects on EFL vocabulary learning and reading comprehension. Frontiers in Psychology Advance online publication. https://doi.org/10.3389/fpsyg.2020.602520

[78] Yanguas, I. (2009). Multimedia glosses and their effect on L2 text comprehension and vocabulary learning. Language Learning \& Technology, 13(2), 48-67.

[79] Zarei, A. A., \& Mahmoodzadeh, P. (2014). The effect of multimedia glosses on L2 reading comprehension and vocabulary production. Journal of English Language and Literature, 1(1), 1-7.

[80] Zheng, Y., \& Cheng, L. (2008). Test review: College English Test (CET) in China. Language Testing, 25, $408-417$. https://doi.org/10.1177/0265532208092433

[81] Zolfagharijjooya, S., Jafarigohar, M., \& Soleiman, H. (2013). The differential effects of glossing for different parts of speech on vocabulary retention and reading comprehension. International Journal of English and Education, 2(3), 346-360.

Andrea Lofgren is a $\mathrm{PhD}$ Candidate in Language and Literacy and a part-time instructor in the Department of Middle and Secondary Education at Georgia State University. She currently works as Editorial Assistant for Ubiquity- The Journal of Literature, Literacy, and the Arts. Her areas of research interest include vocabulary acquisition among English language learners, multicultural teaching practices, and social justice activism. 